\title{
Protective effect of sucrose on the survival of mouse and rat embryos stored at $0^{\circ} \mathrm{C}$
}

\author{
M. Kasai, K. Niwa and A. Iritani \\ Department of Animal Science, College of Agriculture, Kyoto University, Kyoto 606, Japan
}

\begin{abstract}
Summary. Mouse and rat embryos were stored at $0^{\circ} \mathrm{C}$ for $24-120 \mathrm{~h}$ in PBS containing sucrose. Higher proportions of mouse morulae developed into expanded blastocysts in culture when they were stored in $0.25,0.5$ or $0.75 \mathrm{M}$-sucrose than in $0,0.1$ or $1.0 \mathrm{M}$ sucrose. The greatest survival rates were obtained with $0.75 \mathrm{M}$-sucrose when examined after $48(72 \%), 72(62 \%)$ and $96(41 \%)$ h of storage. No rat morulae developed after storage at $0^{\circ} \mathrm{C}$ for $24 \mathrm{~h}$ in PBS, but when 0.5 or $0.75 \mathrm{M}$-sucrose was added to the storage medium, $50-68 \%$ of embryos developed into blastocysts in culture, the proportions decreasing until they reached $15-21 \%$ after $120 \mathrm{~h}$ of storage. Mouse and rat embryos stored at $0^{\circ} \mathrm{C}$ for $3-4$ days were transferred to recipients, and $2 / 2$ mice and $1 / 2$ rats delivered full-term young. When mouse embryos stored in $0.75 \mathrm{M}$-sucrose were frozen to $-196^{\circ} \mathrm{C}$ or when freshly collected frozen-thawed embryos were stored at $0^{\circ} \mathrm{C}$, embryonic survival was improved when the embryos were incubated for 1-6 $\mathrm{h}$ between the two treatments.
\end{abstract}

\section{Introduction}

The freezing technique first developed by Whittingham, Leibo \& Mazur (1972) and Wilmut (1972) has made it possible to preserve mammalian embryos in liquid nitrogen for a prolonged period. Embryos can be stored at temperatures above freezing for only a limited period, but the technique is useful because it is more convenient than freezing. The viability of mouse morulae stored at $0^{\circ} \mathrm{C}$ was much improved when $0.75 \mathrm{M}$-sucrose was added in phosphate-buffered saline (Kasai, Niwa \& Iritani, 1981), but the concentration was adopted arbitrarily, and whether sucrose is effective for storing embryos of other species is not known. In the present study, we examined the effects of sucrose concentration and duration of storage on the survival of freshly collected mouse and rat morulae. We also preserved mouse embryos at $0^{\circ} \mathrm{C}$ in the presence of sucrose before or after freezethawing.

\section{Materials and Methods}

Female ICR mice (4-5 weeks old) were induced to superovulate by i.p. injections of 5 i.u. PMSG and 5 i.u. hCG given $48 \mathrm{~h}$ apart, and were mated. The morulae were flushed from the excised uteri with modified phosphate-buffered saline (PBS: Whittingham, 1971) 79-81 h after the injection of hCG. Similar morulae were obtained, by flushing the uteri, from mature Wistar rats on Day 4 of pregnancy (Day 1 is the day on which spermatozoa are found in the vagina) after natural mating.

Embryos (3-13) were pipetted into $0.2-0.4 \mathrm{ml}$ PBS containing $0,0.1,0.25,0.5,0.75$ or $1.0 \mathrm{M}^{-}$ sucrose in a glass test tube at $0^{\circ} \mathrm{C}$ in an ice bath. After the test tubes were kept for $24-120 \mathrm{~h}$, the 
contents of each tube were emptied into a watch glass and the embryos were directly pipetted into fresh PBS at room temperature. The recovered embryos were washed twice in PBS and then cultured in $0.4 \mathrm{ml} \mathrm{Krebs-Ringer-bicarbonate} \mathrm{(KRB)} \mathrm{medium} \mathrm{(Toyoda} \mathrm{\&} \mathrm{Chang,} \mathrm{1974)} \mathrm{under}$ paraffin oil in a $\mathrm{CO}_{2}$ incubator $\left(5 \% \mathrm{CO}_{2}\right.$ in air at $\left.37^{\circ} \mathrm{C}\right)$. The survival of the embryos was assessed by their ability to develop into expanded blastocysts during $48 \mathrm{~h}$ (mouse) or into blastocysts with a blastocoele larger than the inner cell mass during $24 \mathrm{~h}$ (rat). To examine the further development of embryos stored for 3-4 days with sucrose at $0^{\circ} \mathrm{C}$, embryos that were morphologically normal after culture for 19-20 h (mouse) and 5-6 h (rat) were transferred into the uterine horns of pseudopregnant recipients on Day 3 (mouse) and Day 4 (rat), respectively. The recipients were allowed to litter.

Mouse morulae were also stored at $0^{\circ} \mathrm{C}$ in medium containing $0.75 \mathrm{M}$-sucrose for $24-120 \mathrm{~h}$ and then frozen-thawed or frozen-thawed first and then stored at $0^{\circ} \mathrm{C}$ in $0.75 \mathrm{M}$-sucrose for $24-120 \mathrm{~h}$. Some of the embryos were incubated for 1,3 or $6 \mathrm{~h}$ in a modified $\mathrm{KRB}$ medium at $37^{\circ} \mathrm{C}$ between the two treatments. Embryos were frozen by a 3-step procedure (Kasai et al., 1980). The embryos (4-20) were pipetted into $0.2 \mathrm{ml}$ PBS containing 2.0 M-DMSO in a glass test tube $(10 \times 100 \mathrm{~mm})$ precooled in an ice-bath. After seeding in an ethanol bath at $-7^{\circ} \mathrm{C}$, tubes were cooled by stepwise transfer into $-20^{\circ} \mathrm{C}$ ethanol, liquid nitrogen vapour at $\sim-100^{\circ} \mathrm{C}$ and liquid nitrogen at 10 -min intervals. Samples were thawed rapidly by agitation in $\sim 35^{\circ} \mathrm{C}$ water. DMSO was removed by transferring the embryos into PBS containing 2.0 M-DMSO + 0.5 M-sucrose ( $1-2 \mathrm{~min}$ ), then into PBS with 0.5 M-sucrose and finally into fresh PBS (Kasai et al., 1980). Survival of the embryos was assessed in vitro as described above.

\section{Results}

\section{Unfrozen mouse and rat morulae}

As shown in Table 1 , mouse morulae stored at $0^{\circ} \mathrm{C}$ in the presence of $0,0.1$ or $1.0 \mathrm{M}$-sucrose lost their ability to develop into expanded blastocysts within 72,96 and $96 \mathrm{~h}$ of storage, respectively. In the samples containing $0.25,0.5$ or $0.75 \mathrm{M}$-sucrose, however, survival times were longer; the greatest survival rates were obtained with $0.75 \mathrm{M}$-sucrose when embryos were examined after 48,72 and $96 \mathrm{~h}$ of storage (72, 62 and $41 \%$, respectively) and with $0.5 \mathrm{M}$-sucrose after $120 \mathrm{~h}$ of storage $(28 \%)$. Of 15 and 16 embryos which had been stored at $0{ }^{\circ} \mathrm{C}$ with $0.75 \mathrm{M}$-sucrose for 3 and 4 days and transferred to 2 recipients, 5 and 6 young were born on Days 20 and 19, respectively.

When rat morulae were stored for $24 \mathrm{~h}$ at $0^{\circ} \mathrm{C}$ (Table 2), no embryos developed after storage in PBS. In contrast, when 0.5 or $0.75 \mathrm{M}$-sucrose was added in PBS, $50-68 \%$ of embryos developed in

Table 1. Percentage survival of mouse morulae* assessed by their ability to develop to expanded blastocysts in culture after storage for various periods at $0^{\circ} \mathrm{C}$ in $\mathrm{PBS}$ containing sucrose

\begin{tabular}{lrrrr}
\hline $\begin{array}{c}\text { Sucrose } \\
\text { conc. } \\
\text { (M) }\end{array}$ & \multicolumn{4}{c}{ Duration of storage (h) } \\
\cline { 2 - 5 } & 48 & 72 & 96 & 120 \\
\hline 0 & 28 & 0 & 0 & - \\
$0 \cdot 1$ & 30 & 23 & 0 & - \\
$0 \cdot 25$ & 56 & 50 & 21 & 10 \\
$0 \cdot 5$ & 69 & 59 & 27 & 28 \\
0.75 & 72 & 62 & 41 & 17 \\
$1 \cdot 0$ & 24 & 3 & 0 & - \\
\hline
\end{tabular}

* Thirty embryos were stored and 26 -30 embryos were recovered for each treatment. 
Table 2. Percentage survival ${ }^{*}$ of rat morulae assessed by their ability to develop to blastocysts in culture after storage for various periods at $0^{\circ} \mathrm{C}$ in PBS containing sucrose

\begin{tabular}{lrrrrr}
\hline $\begin{array}{c}\text { Sucrose } \\
\text { conc. } \\
(\mathrm{M})\end{array}$ & \multicolumn{5}{c}{ Duration of storage (h) } \\
\cline { 2 - 6 } & 24 & 48 & 72 & 96 & 120 \\
\hline 0 & 0 & 0 & 0 & $\overline{25}$ & - \\
0.5 & 50 & 30 & 32 & 45 & 21 \\
0.75 & 68 & 42 & 45 & 45 & \\
\hline
\end{tabular}

* Twenty embryos were stored and 19-20 embryos were recovered for each treatment.

subsequent culture, the proportions decreasing gradually until they reached $15-21 \%$ after $120 \mathrm{~h}$ of storage. Of 10 and 22 embryos transferred to recipients after storage at $0^{\circ} \mathrm{C}$ with $0.75 \mathrm{M}$-sucrose (for 3 and 4 days, respectively), 8 young were born from the latter recipient on Day 23.

\section{Frozen mouse morulae}

When embryos stored with $0.75 \mathrm{M}$-sucrose for $24-120 \mathrm{~h}$ at $0^{\circ} \mathrm{C}$ were recovered and then immediately frozen (Table 3), morphologically normal embryos were recovered just after thawing, but most of them were injured during the removal of DMSO; they were able to survive if an incubation period of 1-6 $\mathrm{h}$ was incorporated between refrigeration and freezing. When freshly collected frozen-thawed embryos were stored at $0^{\circ} \mathrm{C}$ with $0.75 \mathrm{M}$-sucrose (Table 3), incubation for $\mathrm{l}-6 \mathrm{~h}$ after thawing increased the survival proportions considerably, but the duration of the incubation did not affect the survival rates.

Table 3. Percentage survival of mouse morulae assessed by their ability to develop to expanded blastocysts in culture after storage at 0 and $-196^{\circ} \mathrm{C}$ or at -196 and $0^{\circ} \mathrm{C}$

\begin{tabular}{|c|c|c|c|c|c|c|c|}
\hline \multirow{2}{*}{$\begin{array}{c}\text { First } \\
\text { storage } \\
\left({ }^{\circ} \mathrm{C}\right)^{*}\end{array}$} & \multirow{2}{*}{$\begin{array}{c}\text { Second } \\
\text { storage } \\
\left({ }^{\circ} \mathrm{C}\right)^{*}\end{array}$} & \multirow{2}{*}{$\begin{array}{c}\text { Duration } \\
\text { of } \\
\text { incubation } \\
\text { (h) } \dagger\end{array}$} & \multicolumn{5}{|c|}{ Duration of storage at $0^{\circ} \mathrm{C}(\mathrm{h}) \ddagger$} \\
\hline & & & 24 & 48 & 72 & 96 & 120 \\
\hline \multirow[t]{4}{*}{0} & -196 & 0 & 8 & 0 & 0 & 4 & 0 \\
\hline & & 1 & 76 & 50 & 57 & 31 & 50 \\
\hline & & 3 & 64 & 72 & 75 & 22 & 13 \\
\hline & & 6 & 76 & 67 & 53 & 14 & 40 \\
\hline \multirow[t]{4}{*}{-196} & 0 & 0 & 67 & 12 & 9 & 0 & 0 \\
\hline & & 1 & 93 & 89 & 65 & 44 & 22 \\
\hline & & 3 & 96 & 90 & 57 & 52 & 39 \\
\hline & & 6 & 93 & 94 & 76 & 50 & 33 \\
\hline
\end{tabular}

* Only morphologically normal embryos after the first storage (13-29 embryos for each treatment) were re-stored.

$\dagger$ Embryos were incubated at $37^{\circ} \mathrm{C}$ after the first storage.

$\ddagger$ Embryos were stored in PBS containing $0.75 \mathrm{M}$-sucrose.

\section{Discussion}

Few attempts have been made to preserve mouse and rat embryos at temperatures above freezing by using protective agents. In a previous study, we reported that sucrose had a protective effect on mouse embryos stored at $0^{\circ} \mathrm{C}$ (Kasai et al., 1981). The results of the present study show that the 
concentration we used $(0.75 \mathrm{M})$ is also adequate for rat morulae. The nature of the protective effect is not clear but considering the extremely shrunken state of the embryos stored with sucrose at $0^{\circ} \mathrm{C}$ (cell volume of unfertilized mouse oocytes decreases to about $40 \%$ of the original: unpublished observation), dehydration is probably the main factor. Cells are also dehydrated during slow freezing (mouse unfertilized oocytes shrink to $70 \%$ by $-20^{\circ} \mathrm{C}$, to $60 \%$ by $-40{ }^{\circ} \mathrm{C}$ and to about $40 \%$ at $-100^{\circ} \mathrm{C}$; Leibo, 1977), and it is thought that cells are injured by long exposure to the intra- and extracellular concentrated solution at relatively high subzero temperatures (solution effects) (Mazur, 1970). However, at $0^{\circ} \mathrm{C}$, exposure in a properly balanced salt solution to a non-toxic nonpermeable non-electrolyte such as sucrose, which causes partial dehydration of the embryos, seems beneficial for survival.

Storage of embryos before or after freezing has not been reported so far, but if a refrigeration technique can be used combined with a freezing technique, it will be possible to make the best use of embryonic resources. For example, it would be possible to collect embryos from a group of cyclic animals (e.g. rats) for a few consecutive days and then to freeze them at one time. When many embryos are contained in a sample and enough pseudopregnant recipients are not available, some of the transfers could be postponed; collected embryos could also be transported to a place where freezing apparatus is available. The present results show that it is possible to store mouse embryos in $0.75 \mathrm{M}$-sucrose in PBS before or after freezing and thawing. However, a period of culture in KRB between the two treatments is beneficial to survival. Membranes of the embryos might be injured to some extent after storage or freezing, and these may be repaired during incubation.

Our storage technique, developed for rodent embryos, may also prove to be beneficial for transfers of embryos of domestic animals, provided sucrose has the same effect upon other mammalian embryos.

\section{References}

Kasai, M., Niwa, K. \& Iritani, A. (1980) Survival of mouse embryos frozen and thawed rapidly. J. Reprod. Fert. 59, $51-56$.

Kasai, M., Niwa, K. \& Iritani, A. (1981) Effects of various cryoprotective agents on the survival of unfrozen and frozen mouse embryos. J. Reprod. Fert. 63, 175-180.

Leibo, S.P. (1977) Fundamental cryobiology of mouse ova and embryos. In The Freezing of Mammalian Embryos (Ciba Fdn Symp. No. 52 (new series)), pp. 69. 92. Eds K. Elliott \& J. Whelan. Elsevier/North Holland, Amsterdam.

Mazur, P. (1970) Cryobiology: the freezing of biological systems. Science, N.Y. 168, 939-949.

Toyoda, Y. \& Chang, M.C. (1974) Fertilization of rat eggs in vitro by epididymal spermatozoa and the development of eggs following transfer. J. Reprod. Fert. 36, 9-22.

Whittingham, D.G. (1971) Survival of mouse embryos after freezing and thawing. Nature, Lond. 233, 125126.

Whittingham, D.G., Leibo, S.P. \& Mazur, P. (1972) Survival of mouse embryos frozen to $-196^{\circ} \mathrm{C}$ and $-269^{\circ}$ C. Science, N.Y. 178, 411-414.

Wilmut, I. (1972) Effect of cooling rate, warming rate, cryoprotective agent and stage of development on survival of mouse embryos during freezing and thawing. Life Sci. 11, 1071-1079.

Received 5 November 1982 